\title{
On the crustal bias of repeat stations in Romania
}

\author{
${ }^{1}$ Institute of Geodynamics, Romanian Academy, Bucharest, Romania \\ ${ }^{2}$ Geological Survey, Bucharest, Romania
}

Venera Dobrica $^{1,{ }^{\star}}$, Crisan Demetrescu ${ }^{1}$, Razvan Greculeasa $^{1}$, Anca Isac $^{2}$

\author{
Article history \\ Received October 14, 2011; accepted January 30, 2012. \\ Subject classification: \\ Geomagnetic field, Secular variation, Repeat station network, Romania.
}

\section{ABSTRACT}

A magnetic induction model has been applied to recordings obtained in 2010 during the field campaigns for geomagnetic measurements at the 26 repeat stations of the Romanian secular variation network. The model is based on the observation that a variable external magnetic field induces a response of the Earth's interior not only by electromagnetic induction, but also by magnetic induction in the magnetic rocks above the Curie temperature. The model computes coefficients of a linear relationship between recorded values of a certain geomagnetic element ( $X, Y, Z$, or $F)$ at the repeat station and recorded $X, Y, Z$ values at a reference station (in this case, SUA observatory). Coefficients depend on magnetic permeabilities of rocks beneath the station and stand as a proxy for the anomaly bias characterizing the site. Maps of the lateral variation of this type of information were obtained and discussed.

\section{Introduction}

At present the geomagnetic field is monitored both at ground, by means of magnetic observatories and repeat stations, and from space, by means of satellites, leading to complex studies and modeling of the geomagnetic field [e.g. Olsen et al. 2007, Finlay et al. 2010, Matzka et al. 2010, Thébault et al. 2010, Mandea and Korte 2011].

At global scale the secular variation is found by processing continuous records of the geomagnetic field at magnetic observatories. Generally, a country of Romania's size has only one observatory. The Romanian one, namely Surlari geomagnetic observatory (IAGA code, SUA), was established in 1942.

The information from geomagnetic observatories is supplemented at regional level by repeated measurements in a network called secular variation network. In the last years, as a result of a better understanding of the importance of repeat station data in learning about the spatial-temporal evolution of the geomagnetic field, a project is going on at European level, MagNetE (Magnetic Network of Europe), initiated in 2003 [Korte and Mandea 2003], on systematic measurements in national secular variation networks. As a result of this initiative the map of declination in Europe at the epoch 2006 was published [Duma et al. 2012].
The repeat station data were discussed in several studies [e. g. Korte and Thébault 2007, Thébault 2008] as regards the crustal bias and/or modelling at regional scale.

In Romania, since 1964 systematic geomagnetic measurements have been done in a network of 26 repeat stations. Reports on measurement results and their interpretation in terms of secular variation and normal field distributions were published by Atanasiu et al. [1965, 1967, 1970, 1974, 1976], Anghel et al. [1980], Demetrescu et al. [1985]. Recently, Demetrescu et al. [2011] have reported measurements of the horizontal component at the repeat stations, in the time interval 1980-2004, interpreted according to insights from the analysis of long time series provided by geomagnetic observatories [Demetrescu and Dobrica 2005, 2012]. Beginning with the 2009 campaign, recording fluxgate and proton magnetometers have been deployed, in order to better control the data correction for diurnal and disturbed variations.

In this study we focus on the recordings taken in 2010 in the stations of the repeat network, by means of a LEMI-018 magnetic variometer and of a G-856 Geometrics proton magnetometer, in order to infer information on the lateral variation on the Romanian territory of the crustal bias that characterizes each repeat station.

\section{Method}

Usually, the interpretation of the geomagnetic data from magnetometric arrays is based on the assumption that the external variable magnetic field induces in the conductive structures of subsurface electrical currents that, in turn, produce secondary, detectable magnetic fields. Our method is based on the observation that the variable external magnetic field induces variable internal magnetic fields not only by electromagnetic induction, but also by magnetic induction in rocks below the Curie temperature. In case of pure magnetic induction, the temporal variation of the field components at a given observing site is a linear combination of the components of the magnetic inducing force [Demetrescu et al. 1985, 1988], 


$$
\Delta E^{(S)}(t)=\sum_{k=1}^{3} C_{k}^{E} \Delta F_{k}(t)
$$

where $\Delta$ represents variations about temporal averages, $E^{(S)}$ is the geomagnetic field component at the station $S$ ( $E$ can be $\mathrm{X}, \mathrm{Y}, \mathrm{Z}$, or $\mathrm{F}), F_{k}, k=1 \ldots 3$, are the components of the inducing magnetic force and $C_{k}^{E}$ are coefficients that depend on the effective magnetic permeability characterizing the site. The calculated values $\left(\Delta E^{(S)}\right.$ calc) of the model would represent the pure magnetic induction component of the observed signal and the residuals $\left(\Delta E^{(S)_{\text {res }}}=\Delta E^{(S)}-\Delta E^{(S)}\right.$ calc $)$ would contain information on electromagnetic induction in the Earth at the observing site. The coefficients $C_{k}^{E}$, can be determined by a standard least squares procedure and be mapped, resulting in images of the lateral distribution of the magnetic properties characterizing the volume of rocks above the Curie temperature (generally the crust). In order to ensure the comparability of the coefficients obtained for the stations, the recordings at all stations should be simultaneous, to meet the requirement that variations recorded at each station sample the same time interval as the external inducing force. Consequently, temporal averages mentioned above refer to the common recording time interval.

So far, the method has been successfully applied in the case of the Romanian network of repeat stations [Demetrescu et al. 1985] and the network of European geomagnetic observatories [Demetrescu et al. 1988, Demetrescu and Andreescu 1992, Demetrescu and Andreescu 1994, Demetrescu and Dobrica 2003] for the case of the solar-sunspot-cycle related variations, as well as in the case of the Hokkaido magnetometric array [Dobrica et al. 2008/2009] for the diurnal variation. In the present paper we apply this method to variations recorded at the Romanian network of repeat stations in a time span of several hours. Slight changes in the method, discussed in the next two sections, have been introduced due to the particular setting of our measurements.

\section{Repeat station and observatory data}

The input data in the magnetic induction model are the three orthogonal components and total intensity of the geomagnetic field observed in the Romanian network of repeat stations and the components of the inducing magnetic force. In the absence of independent data on the external geomagnetic field related to the variations observed (i.e. the field produced by the ionospheric and magnetospheric current systems responsible for the regular diurnal variation (Sq) and, respectively, for the geomagnetic activity), we took as estimates for the components of the inducing magnetic force, the components of the variation at a nearby geomagnetic observatory (a reference station, as is usually done in the interpretation of data from magnetometer arrays [Gamble et al. 1979, Gough and Ingham 1983, Harada et al. 2004]). In this study, the Surlari geomagnetic observatory has been used as the reference station, so the input magnetic inducing force in the model is in fact a resultant of the external field and the induced response of the Earth beneath the observatory. As the latitudinal spread of the study territory is rather small in comparison to the lateral scale of the Sq current system, we did not account for the small possible variation of the external Sq field from station to station. The actual equations expanded from Equation (1) read:

$$
\begin{aligned}
& \Delta X^{(S)}(t)=\alpha_{x} \Delta X^{S U A}(t)+\alpha_{y} \Delta Y^{S U A}(t)+\alpha_{z} \Delta Z^{S U A}(t) \\
& \Delta Y^{(S)}(t)=\beta_{x} \Delta X^{S U A}(t)+\beta_{y} \Delta Y^{S U A}(t)+\beta_{z} \Delta Z^{S U A}(t) \\
& \Delta Z^{(S)}(t)=\gamma_{x} \Delta X^{S U A}(t)+\gamma_{y} \Delta Y^{S U A}(t)+\gamma_{z} \Delta Z^{S U A}(t) \\
& \Delta F^{(S)}(t)=\zeta_{x} \Delta X^{S U A}(t)+\zeta_{y} \Delta Y^{S U A}(t)+\zeta_{z} \Delta Z^{S U A}(t)
\end{aligned}
$$

The distribution of the 26 repeat stations and SUA observatory over the national territory is presented in Figure 1 and the geographical coordinates are given in Table 1.

The measurements were taken in 2010 during four field campaigns: June 17 to July 7, July 30 to August 18, September 14 to 22 , and October $1^{\text {st }}$ to 14 . At each station the field components $\mathrm{X}, \mathrm{Y}$, and $\mathrm{Z}$ were recorded for 7-8 hours, generally between 8-17 standard local time (SLT) (5-14 UT), by means of a LEMI-018 magnetic variometer. We also recorded, by means of a G-856 Geometrics proton magnetometer, the total field intensity, F. One minute data have been used in the subsequent processing. As an example of data appearance we show, in Figure 2, the records in case of three stations, as compared to observatory recordings. Generally low geomagnetic activity characterized the recording time span, but disturbed days were also present in a few instances. A strong disturbance seen on data in the recordings of Lipova station, on the $4^{\text {th }}$ of August is shown as an example as well. The geomagnetic conditions during the measurement campaigns can be seen in Figure 3, where the field evolution recorded by the geomagnetic observatory during the four campaigns is shown together with the evolution of the Dst index.

\section{Results and discussion}

Results for each repeat station consist of the coefficients of Equation (2), the calculated values of the model, and the residuals. In Figure 4 we give, as an example, the calculated field and the residuals of the induction model for X, Y, Z, and $\mathrm{F}$, in case of Cluj repeat station. Figure 5 synthetically illustrates, by means of the standard deviation about the mean (SD), the variability of initial data, of calculated ones, and of residuals for the 26 stations, in case of each of the four geomagnetic elements investigated. Generally the calculated values, that is the magnetically induced response of rocks above Curie temperature, explain the most part of the recorded signal in all components. The $\mathrm{X}$ record at station no. 24 and the $\mathrm{Y}$ record at station no. 18 could not be used due to a malfunction 
Figure 1. The Romanian repeat stations network and Surlari geomagnetic observatory (SUA)

Table 1. Geographical coordinates of the repeat stations of the Romanian network.

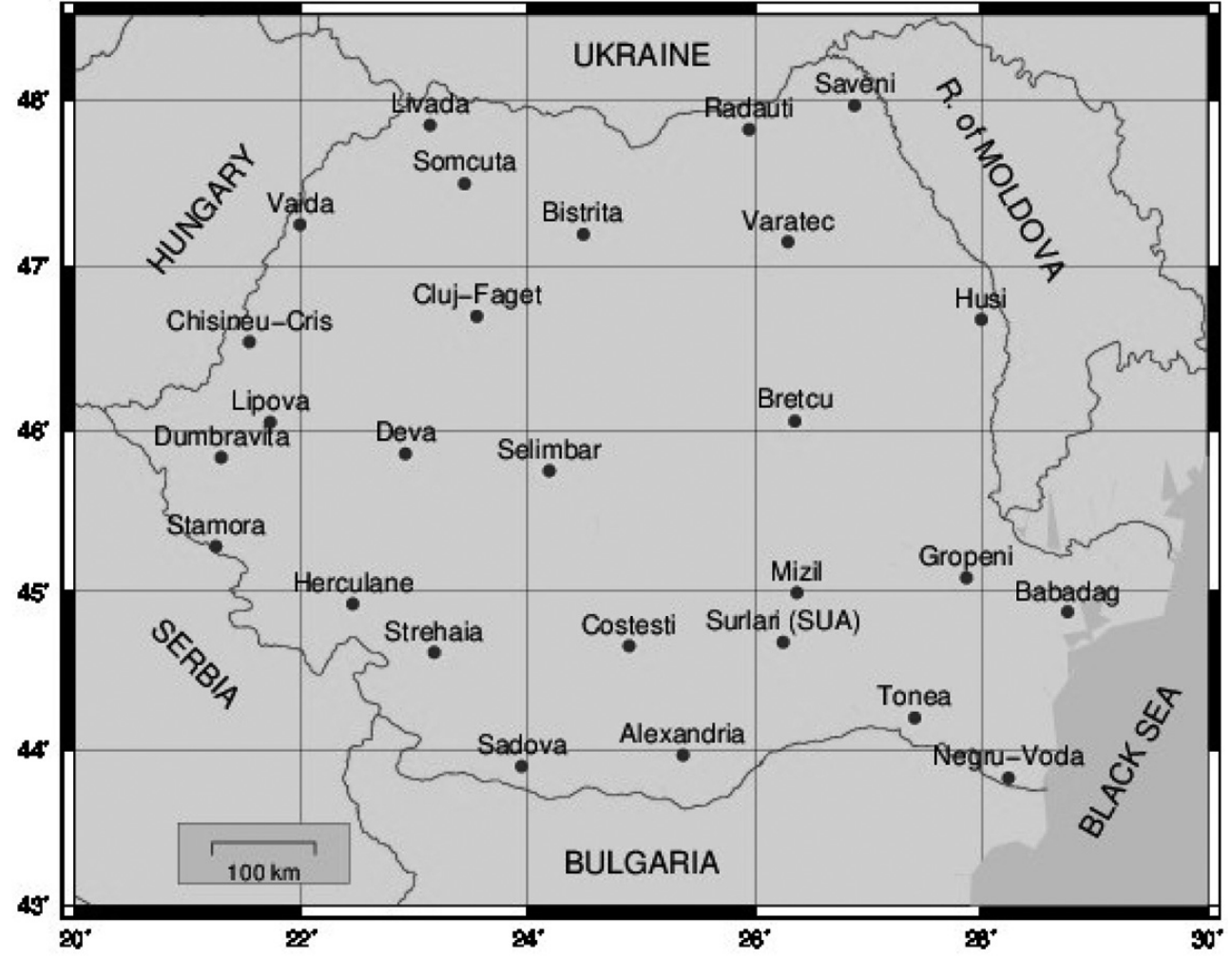

\begin{tabular}{|c|c|c|c|}
\hline No. & Station & $\begin{array}{l}\text { Latitude } \\
\text { (degrees) }\end{array}$ & $\begin{array}{r}\text { Longitude } \\
\text { (degrees) }\end{array}$ \\
\hline 1 & Saveni & 47.96593 & 26.88277 \\
\hline 2 & Livada & 47.84867 & 23.13362 \\
\hline 3 & Radauti & 47.82142 & 25.94800 \\
\hline 4 & Somcuta & 47.49997 & 23.43900 \\
\hline 5 & Vaida & 47.25157 & 21.98520 \\
\hline 6 & Bistrita & 47.19485 & 24.48570 \\
\hline 7 & Varatec & 47.15150 & 26.29175 \\
\hline 8 & Cluj-Faget & 46.69750 & 23.54715 \\
\hline 9 & Husi & 46.67880 & 28.00265 \\
\hline 10 & Chisineu-Cris & 46.54443 & 21.53978 \\
\hline 11 & Bretcu & 46.05767 & 26.35652 \\
\hline 12 & Lipova & 46.05202 & 21.72387 \\
\hline 13 & Deva & 45.85712 & 22.91722 \\
\hline 14 & Dumbravita & 45.83292 & 21.29002 \\
\hline 15 & Selimbar & 45.75188 & 24.18742 \\
\hline 16 & Stamora & 45.28383 & 21.24357 \\
\hline 17 & Gropeni & 45.08573 & 27.86850 \\
\hline 18 & Mizil & 44.99238 & 26.37497 \\
\hline 19 & Herculane & 44.92215 & 22.44942 \\
\hline 20 & Babadag & 44.87207 & 28.76385 \\
\hline 21 & Costesti & 44.65898 & 24.89332 \\
\hline 22 & Strehaia & 44.61763 & 23.16890 \\
\hline 23 & Tonea & 44.20200 & 27.41502 \\
\hline 24 & Alexandria & 43.96683 & 25.36662 \\
\hline 25 & Sadova & 43.89513 & 23.93970 \\
\hline 26 & Negru-Voda & 43.82022 & 28.24305 \\
\hline 27 & $\begin{array}{c}{ }^{\star} \text { Surlari Geomagnetic } \\
\text { Observatory (SUA) }\end{array}$ & 44.68000 & 26.25330 \\
\hline
\end{tabular}


DOBRICA ET AL.
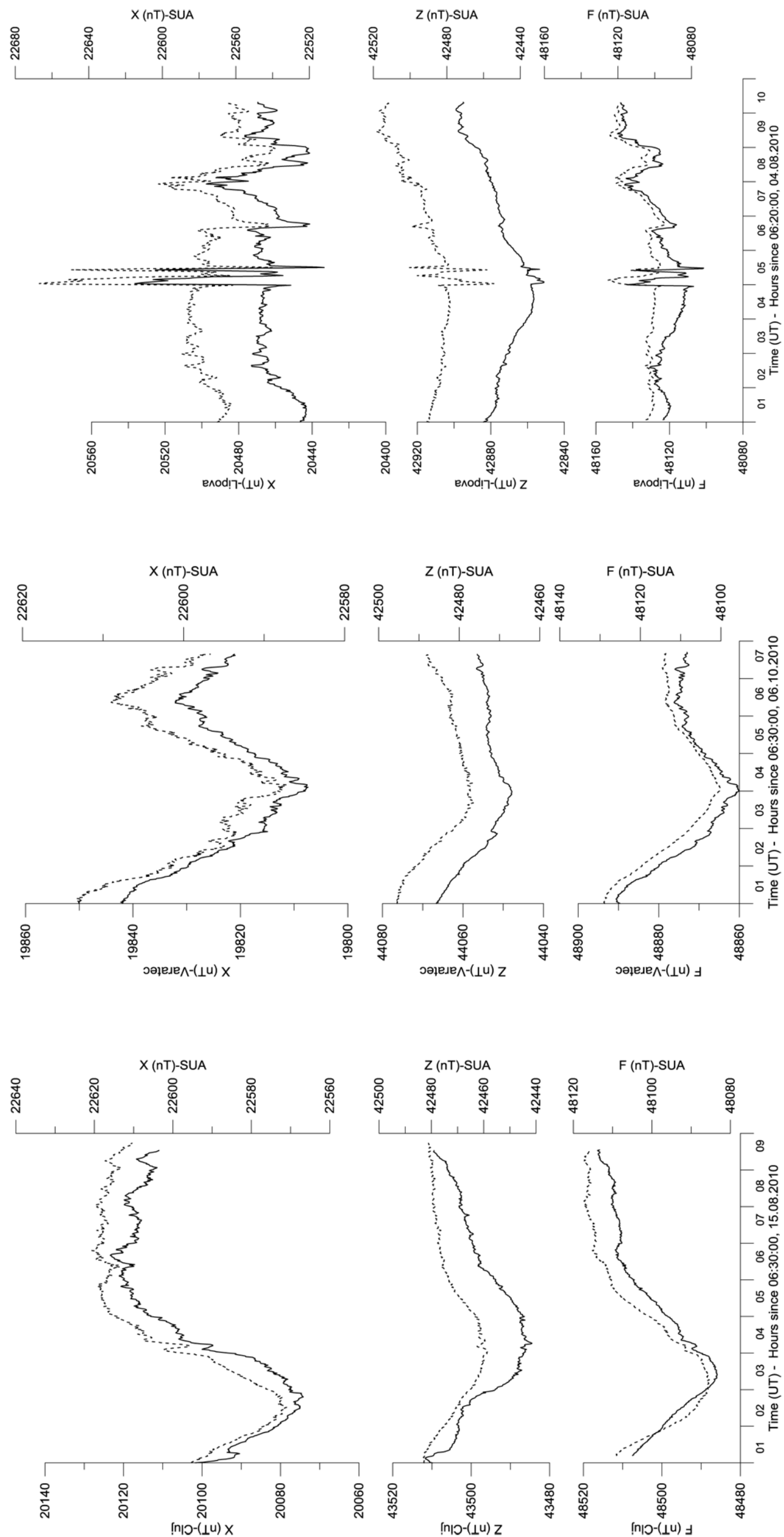

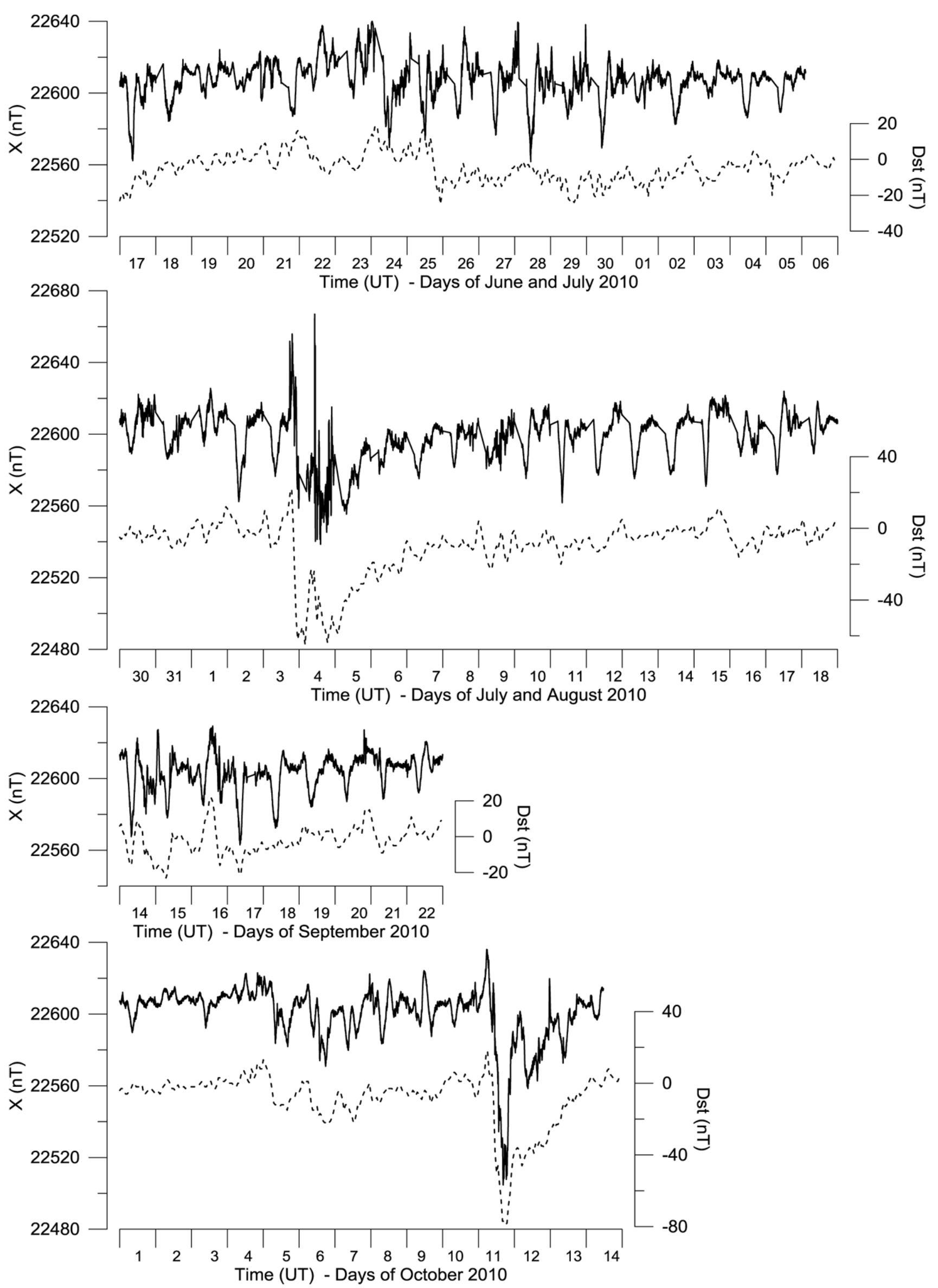

Figure 3. The horizontal northward component evolution recorded at SUA during the field campaigns. The Dst index plotted along illustrates the evolution of the geomagnetic activity. 

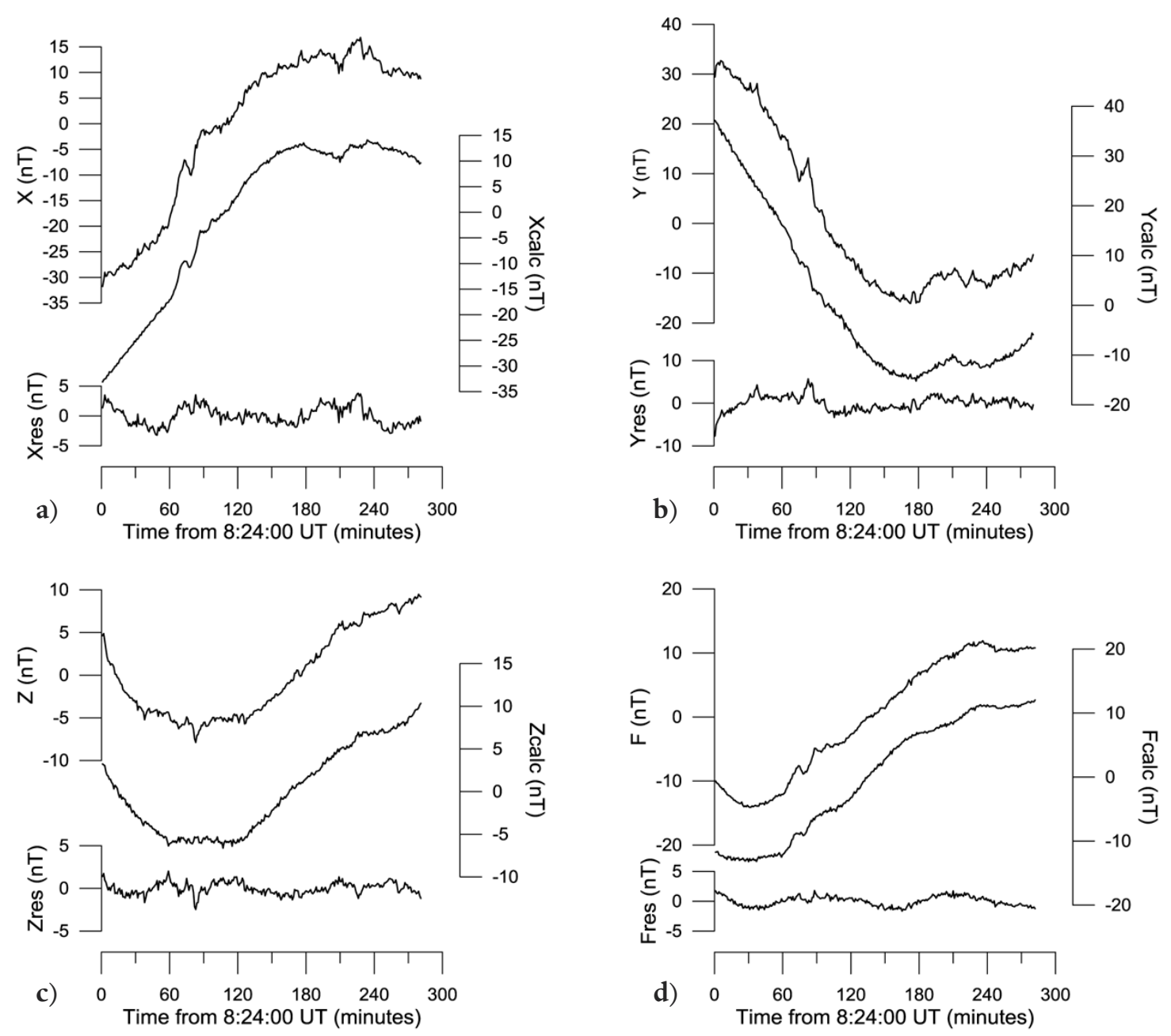

Figure 4. Example of modeling (Cluj station): a) the north component (X); b) the east component (Y); c) the vertical component (Z); d) the total field (F). In each plot the recorded data (upper curve), the calculated values of the model (middle curve) and the residuals (lower curve) are shown.
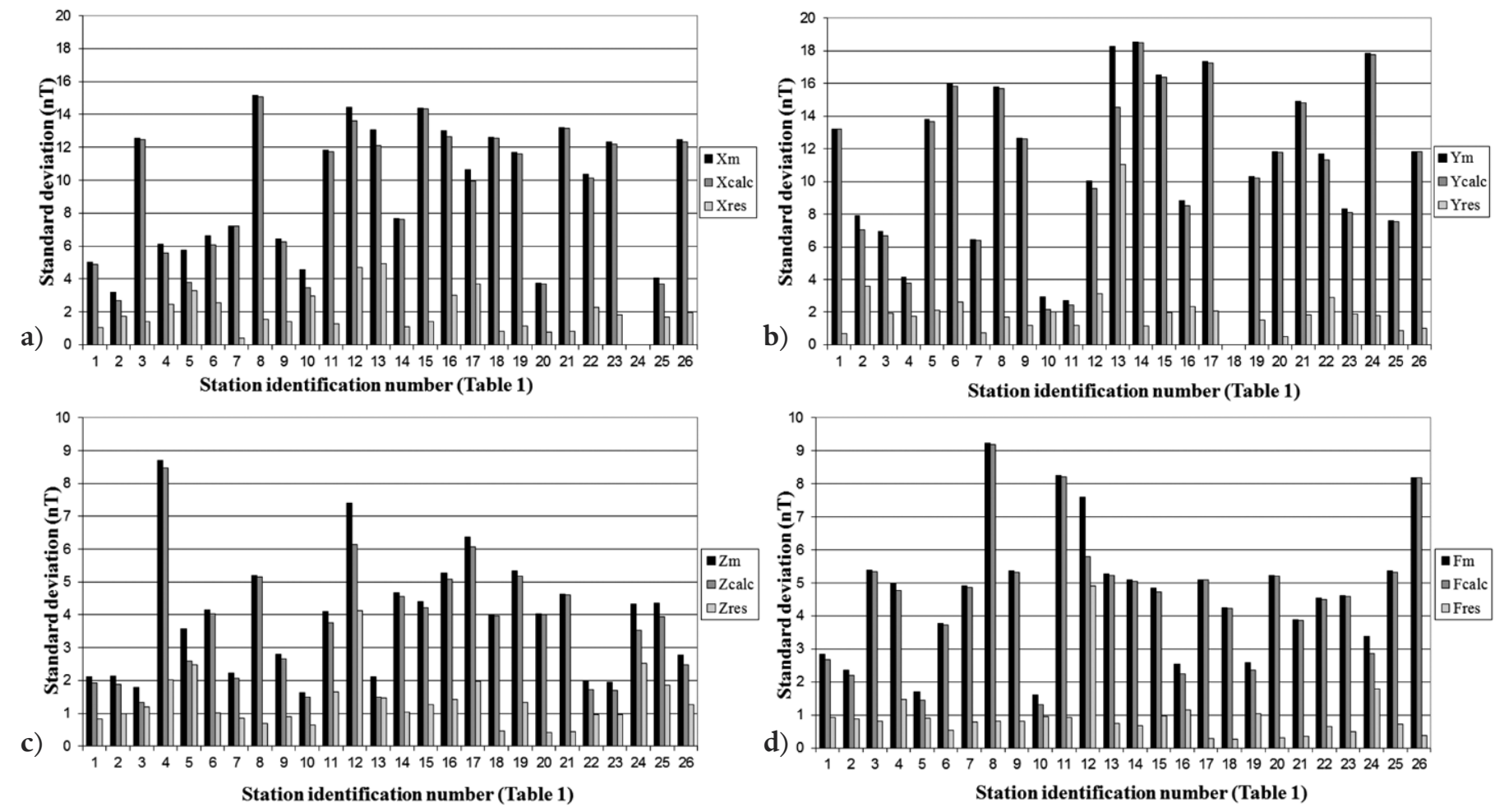

Figure 5. Standard deviation about the mean of raw (measured) data, calculated values of the magnetic induction model, and model residuals for the 26 stations of the repeat network (identification numbers as in Table 1). a) X; b) Y; c) Z; d) F. 

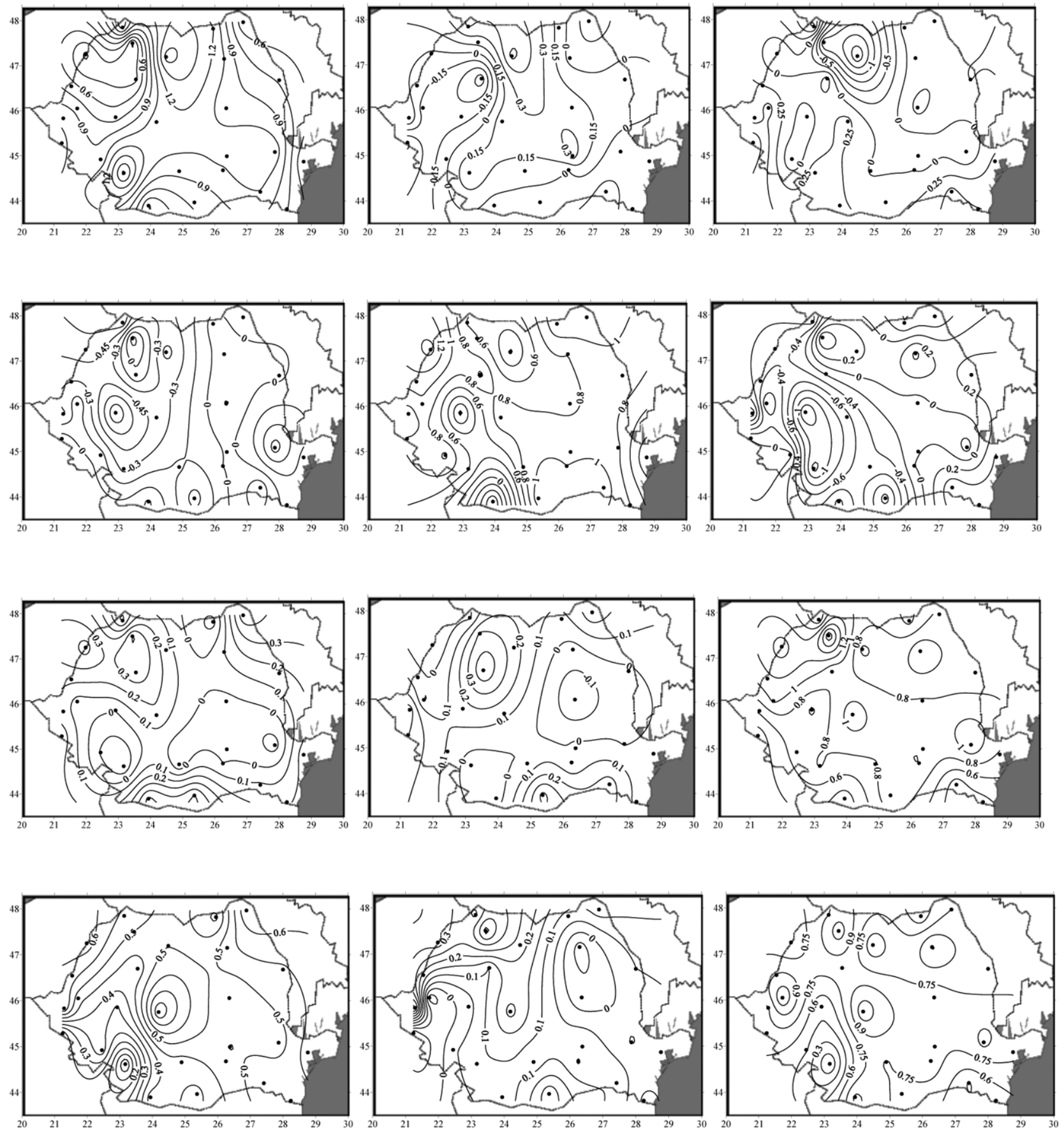

Figure 6. The lateral variation of the repeat stations coefficients. From top to bottom: $\alpha_{x}, \alpha_{y}, \alpha_{z} ; \beta_{x}, \beta_{y}, \beta_{z} ; \gamma_{x}, \gamma_{y}, \gamma_{z} ; \zeta_{x}, \zeta_{y}, \zeta_{z}$.

of the recorder. The corresponding SD analysis and the coefficient values are not displayed in Figure 5 and respectively in Figure 6. The ratio of residuals $S D$ to calculated values $S D$ is, however, larger in case of the vertical component, meaning that the latter is more responsive to electromagnetic induction than the horizontal components, which are more responsive to the magnetic induction. In case of $Z$, the Lipova station shows the largest residuals $\mathrm{SD}$, of about $\pm 4 \mathrm{nT}$, and individual residual values that reach $30 \mathrm{nT}$, which is related to the geomagnetic storm that occurred during measurements. The $Z$ residuals for other stations are of the order of $\pm 1 \mathrm{nT}$ (18 stations) and of $\pm 2 \mathrm{nT}$ (7 stations). The accuracy of coefficients varies between $3 \%$ and $10 \%$ of the coefficient values.
In Figure 6 we present maps of the lateral variation of the coefficients we determined in case of the four geomagnetic elements measured. In order to compare coefficients (and consequently magnetic properties of crust) at different stations, the ideal situation would be to have simultaneous measurements at all network stations, to ensure that the same inducing field is applied to the laterally varying magnetic properties of the study area. Having in view that measurements at the repeat stations were not simultaneous and the daily LT variations have different amplitudes in different days, we selected for each station only data in the time interval common to all stations, namely 8:24-13:05 UT, to ensure at least that we sampled the same part of the regular 

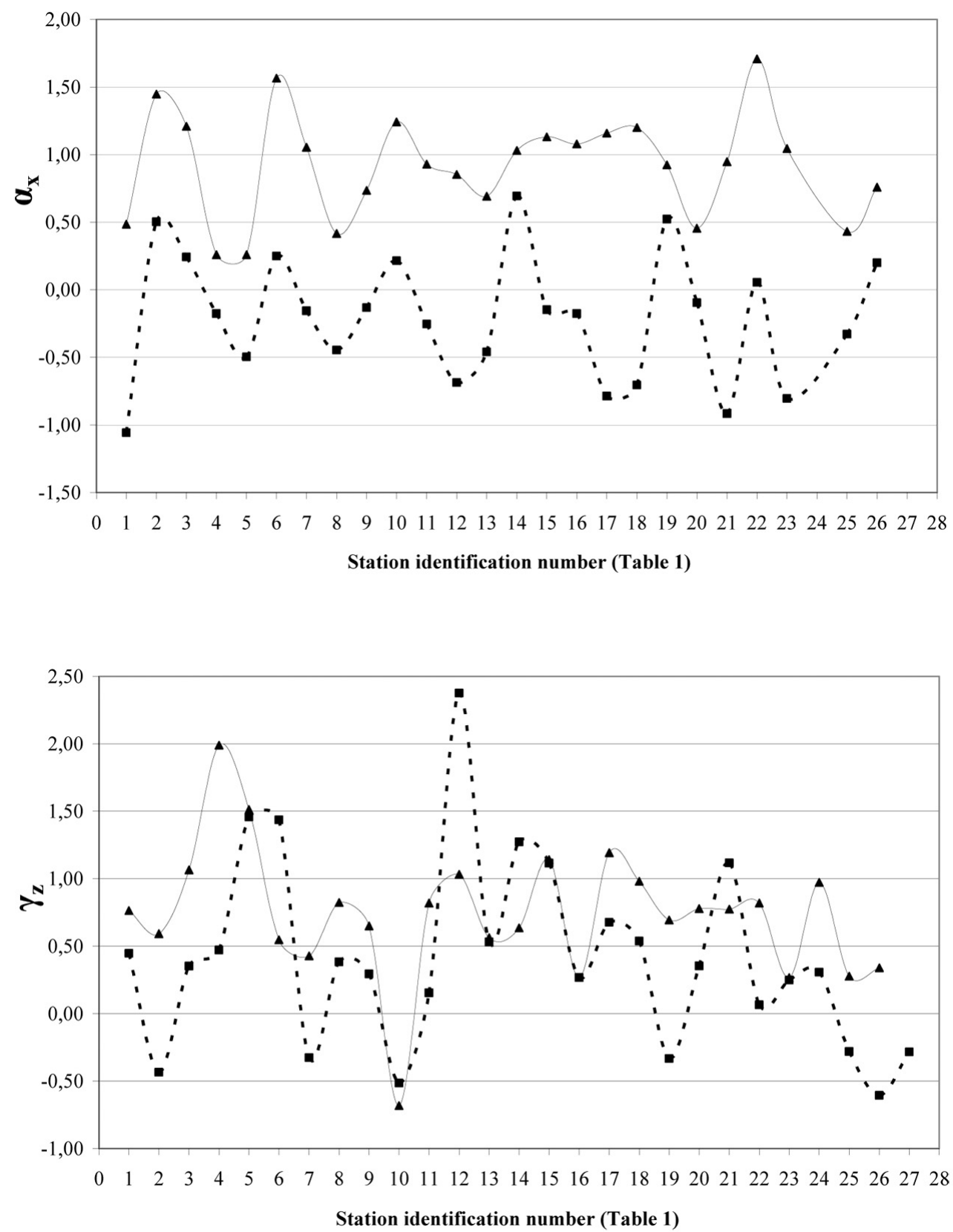

Figure 7. Comparison of the induction model coefficients $\alpha_{x}$ and $\gamma_{z}$ using as proxy for the inducing force SUA (full line) and NGK (broken line).

diurnal variation. The dominant period we sampled this way was the 6-hours harmonic. The higher-frequency UT variations characteristic to the geomagnetic activity were different, of course, in successive days of the survey, but we believe that due to their much lower amplitude (compare 0.5-3 $\mathrm{nT}$ to 40-50 nT; Figure 2) their contribution intervene to a much lesser extent in the actual values of coefficients.

Having in view (1) that coefficients represent the lateral variation of magnetic properties by means of relative values and (2) that we use the proxy for the external variation that induces the magnetic response (records at SUA) we checked if the map patterns are stable when the proxy was changed: we compared our results with coefficients that resulted using a second inducing source, namely the recordings of the Niemegk observatory (NGK). In Figure 7 we plotted the values of coefficients at successively numbered repeat stations
(Table 1) in case of $X$ and $Z$, resulted from the magnetic induction model that used SUA (full line) and NGK (broken line) as reference stations. The agreement between the two sets of coefficients is good, meaning that maps based on the two sets will show similar patterns. Of course, one has to keep in mind the fact that the coefficient values do not represent absolute permeabilities of the underground, but rather quantities relative to each other. Also, the external source and the internal magnetic and electric structures are different for the two observatories, so at least amplitudes of the recorded signal differ in the two cases. Anyway, this issue needs more investigation than that undertaken so far. For the moment, a second type of experiment was not possible, namely checking if the magnetic induction model gives similar results when applied to other time intervals. This would be a matter for future studies. 
Each repeat station was carefully selected when the network was established [Atanasiu et al. 1970], from about 500 stations of the regional geomagnetic survey with 'absolute' measurements done in the 1960 s (a station per $400 \mathrm{~km}^{2}$ ), in order not to reflect regional and local anomalies. The maps reveal, however, some regional pattern, with smaller values in NW, S, and E, and higher values in the central and southwestern part. The lower values might be associated with structure peculiarities of the Pannonian Depression, and Moesian and East-European Platforms, and the higher ones to peculiarities of the eastern and southern Carpathians. As the mapped coefficients reflect magnetic properties of rock volumes down to the Curie temperature surface, the shape and thickness of the lower crust might also contribute to the observed pattern. A quantitative interpretation would be a matter for future research. Of course, a much denser network would be necessary to detect smaller scale structures.

\section{Conclusion}

$\mathrm{X}, \mathrm{Y}, \mathrm{Z}$, and F data recorded in 2010 at the Romanian repeat stations network were used to infer information on the lateral variation of the crustal bias that characterize each station. A magnetic induction model based on the observation that a variable external magnetic field induces a response of the Earth's interior not only by electromagnetic induction, but also by magnetic induction in the magnetic rocks above the Curie temperature, was applied. The calculated values of the model represent the pure magnetic induction component of the observed signal and the residual would contain information on electromagnetic induction in the Earth at the observing site.

The coefficients of the linear model relating the measured values to component of the inducing external field were mapped. The resulting patterns show regional distribution of values that correlate with large scale crustal compartments in the study area, but no quantitative interpretation has been undertaken as yet.

The methodology and the information acquired in this stage of research would contribute to a better correction and interpretation of geomagnetic measurements at repeat stations.

Acknowledgements. The study has been supported by the Institute of Geodynamics (Project 2/2011) and by the Ministry of Education and Research (PN-II UEFISCDI IDEI 0262/2011). We thank two anonymous reviewers for constructive comments that helped improving the manuscript.

\section{References}

Anghel, M., C. Demetrescu and T. Nestianu (1980). Secular variation studies in Romania, Gerlands Beitr. Geophysik, 89, 499-510.

Atanasiu, G., I. Bucur, T. Nestianu, D. Zugravescu and C. Demetrescu (1965). Les valeurs des éléments géomagnetiques, $\mathrm{H}, \mathrm{I}, \mathrm{Z}$ et $\mathrm{F}$ en Transylvanie et au Banat, Rev.
Roum. Géol., Géoph. Géogr., serie de Géophysique, 9, 65-83.

Atanasiu, G., T. Nestianu, D. Zugravescu and C. Demetrescu (1967). Les valeurs normales des éléments géomagnetiques en Transylvanie et au Banat, Rev. Roum. Géol., Géoph. Géogr., serie de Géophysique, 11, 95-103.

Atanasiu, G., T. Nestianu, C. Demetrescu and M. Anghel (1970). Les valeurs normales des éléments géomagnetiques, H, I, Z et F en Roumanie, pour l'époque 1967, Rev. Roum. Géol., Géoph. Géogr., serie de Géophysique, 14, 73-79.

Atanasiu, G., T. Nestianu, C. Demetrescu and M. Anghel (1974). The secular variation of the geomagnetic elements H, Z, and F between 1958-1972 in Romania, Rev. Roum. Géol., Géoph. Géogr., serie de Géophysique, 18, 59-65.

Atanasiu, G., T. Nestianu, C. Demetrescu and M. Anghel (1976). Some aspects of the secular variation of the geomagnetic elements H, Z, F, between 1958-1974 in Romania, Phys. Earth. Planet. Inter., 12, 11-17.

Demetrescu, C., M. Andreescu, T. Nestianu and M. Ene (1985). Characteristics of the secular variation of the geomagnetic field between 1964 and 1981 in Romania, Phys. Earth Planet. Inter., 37, 46-51.

Demetrescu, C., M. Andreescu and T. Nestianu (1988). Induction model for the secular variation of the geomagnetic field in Europe, Phys. Earth Planet. Inter. 50, 261-271.

Demetrescu, C., and M. Andreescu (1992). Magnetic and electromagnetic induction effects in the annual means of geomagnetic elements, In: R.A. Langel and R.T. Baldwin (eds.), Types and Characteristics of Data for Geomagnetic Field Modeling, NASA Conference Publication 3153, 333-341.

Demetrescu, C., and M. Andreescu (1994). Magnetic and electromagnetic induction effects in the annual means of the vertical component of the geomagnetic field at European observatories, Rev. Roum. Geophys., 38, 73-84.

Demetrescu, C., and V. Dobrica (2003). On the electric properties of rocks under the network of European geomagnetic observatories as derived from series of annual means of geomagnetic elements, Romanian Reports in Physics, 55, 411-419.

Demetrescu, C., and V. Dobrica (2005). Recent secular variation of the geomagnetic field: New insights from long series of observatory data, Rev. Roum. Geophys., 49, 63-72.

Demetrescu, C., M. Ene and V. Dobrica (2011). Geomagnetic field change in Romania, 1980-2004, Romanian Journal of Physics, 56, 790-800.

Demetrescu, C., and V. Dobrica (2012). High-frequency ingredients of the secular variation of the geomagnetic field. Insights from long time series of observatory data, Journal of Geophysical Research, submitted. 
Dobrica, V., T. Mogi, C. Demetrescu and M. Takada (2008/2009). Magnetic induction effects of the diurnal variation. Case study - the Hokkaido magnetometer array, Rev. Roum. Geophys., 52-53, 33-47.

Duma, G., B. Leichter and the MagNetE Group (2012). Map of Magnetic Declination in Europe (2006), CCGM.

Finlay, C.C., S. Maus, C.D. Beggan, T.N. Bondar, A. Chambodut, T.A. Chernova, A. Chulliat, V.P. Golovkov, B. Hamilton, M. Hamoudi, R. Holme, G. Hulot, W. Kuang, B. Langlais, V. Lesur, F. J. Lowes et al. (2010). International Geomagnetic Reference Field: the eleventh generation, Geophys. J. Int., 183, 1216-1230.

Gamble, T.D., W.M. Goubau and J. Clarke (1979). Magnetotellurics with a remote magnetic reference, Geophysics, 44, 53-68.

Gough, D.I., and M.R. Ingham (1983). Interpretation methods for magnetometer arrays, Rev. Geophys., 21, 805-827.

Harada, M., K. Hattori, N. Isezaki, T. Nagao and S. Uyeda (2004). Elimination of the effects of external source field from electric and magnetic data on the ground, Proc. IWAM04, Mizunami, Japan, 271-278.

Korte, M., and M. Mandea (2003). Improvements planned for European geomagnetic repeat stations. EOS, Trans., Amer. Geophys. Soc., 84, 160.

Korte, M., and E. Thébault (2007). Geomagnetic repeat station crustal biases and vectorial anomaly maps for Germany, Geophys. J. Int., 170, 81-92; doi:10.1111/j.1365-246 X.2007.03387.x.

Mandea, M., and M. Korte, eds. (2011). Geomagnetic observations and models, IAGA Book Series, vol. 5, doi 10.1007/978-90-481-9858-0, Springer Science B.V., Dordrecht/Heidelberg/London/New York, 343 pp.

Matzka, J., A. Chulliat, M. Mandea, C.C. Finlay and E. Qamili (2010). Geomagnetic Observations for Main Field Studies: From Ground to Space, Space Science Reviews, 155 (1/4), 29-64; doi:10.1007/s11214-010-9693-4.

Olsen, N., G. Hulot and T. J. Sabaka (2007). The Present Field, In: M. Kono (ed.), Treatise on Geophysics, vol. 5: Geomagnetism, Elsevier, 33-75.

Thébault, E. (2008). A proposal for regional modelling at the Earth's surface, R-SCHA2D, Geophys. J. Int., 174, 118-134; doi:10.1111/j.1365-246X.2008.03823.x.

Thébault, E., M. Purucker, K.A. Whaler, B. Langlais and T. J. Sabaka (2010). The Magnetic Field of the Earth's Lithosphere, Space Science Reviews, 155 (1/4), 95-127; doi:10.1007/s11214-010-9667-6.

\footnotetext{
${ }^{\star}$ Corresponding author: Venera Dobrica, Institute of Geodynamics, Romanian Academy, Bucharest, Romania; email: venera@geodin.ro. 